\title{
Radiologic evaluation for volume and weight of remnant lung in living lung donors
}

\author{
Teruaki Mizobuchi, MD, PhD, ${ }^{\mathrm{a}}$ Fengshi Chen, MD, PhD,${ }^{\mathrm{b}}$ Ichiro Yoshino, $\mathrm{MD}, \mathrm{PhD},{ }^{\mathrm{a}}$ \\ Takekazu Iwata, MD, PhD, ${ }^{\mathrm{a}}$ Shigetoshi Yoshida, $\mathrm{MD}, \mathrm{PhD},{ }^{\mathrm{a}}$ Toru Bando, $\mathrm{MD}, \mathrm{PhD},{ }^{\mathrm{b}}$ and \\ Hiroshi Date, $\mathrm{MD}, \mathrm{PhD}^{\mathrm{b}}$
}

\begin{abstract}
Objective: Living-lung donors lose pulmonary function of a right or left lower lobe in exchange for a noble donation; however, Chen and colleagues reported postoperative pulmonary function of the donors was significantly better than the estimated values. The purpose of this study was to investigate if the improvement of postoperative pulmonary function is associated with hypertrophic phenomena of remnant lung.
\end{abstract}

\begin{abstract}
Methods: A total of 35 patients who underwent a right or left lower lobectomy for living-donor lobar lung transplantation in Kyoto University Hospital from 2008 to 2011 were evaluated by means of spirometry (forced vital capacity, forced expiratory volume in 1 second, and diffusing capacity for carbon monoxide), and computed tomography scans both before and 1 year after the surgery. Postoperative predictions of pulmonary function and radiologic parameters were made based on the number of resected segments. The average radiologic density of the lung was determined as follows: (mean computed tomography number +1000$) / 1000$, and weight of the lung was calculated as follows: lung volume $(\mathrm{mL}) \times$ average radiologic lung density $(\mathrm{g} / \mathrm{mL})$. The radiologic analysis was performed on both the surgical and contralateral sides.
\end{abstract}

Results: Postoperative forced vital capacity, forced expiratory volume in 1 second, and diffusing capacity for carbon monoxide were significantly higher than estimated values by $17.3 \% \pm 10.2 \%(P<.0001), 14.7 \% \pm$ $10.2 \%(P<.0001)$, and $10.9 \% \pm 16 . \%(P<.002)$, respectively. Postoperative lung volume and weight of the surgical side were significantly higher than estimated values by $54.4 \% \pm 30.4 \%(P<.0001)$ and $28.1 \%$ $\pm 15.7 \%(P<.0001)$, respectively. On the contralateral side, the postoperative lung volume was significantly higher than the estimated value by $12.6 \% \pm 15.3 \%(P<.0001)$, but postoperative weight was comparable with the estimated value $(-2.3 \% \pm 8.8 \% ; P=.07)$.

Conclusions: Hypertrophic change of the ipsilateral remnant lung may be recognized in living lung donors.

(J Thorac Cardiovasc Surg 2013;146:1253-8)

Living-donor lung transplantation (LDLLT) has been performed successfully and is a surgical option for a critical patient who has a rapidly progressing pulmonary disease. ${ }^{1-3}$ LDLLT usually needs a donation of both a right and a left lower lobe from 2 healthy donors, who sacrifice their pulmonary function for the lobectomy. A lung lobectomy is a standard surgery for primary lung cancer, and a simplified prediction of postoperative pulmonary function based on

\footnotetext{
From the Department of General Thoracic Surgery, ${ }^{\text {a }}$ Chiba University Graduate School of Medicine, Chiba, Japan; and Department of Thoracic Surgery, ${ }^{\mathrm{b}}$ Kyoto University Graduate School of Medicine, Kyoto, Japan.

This study was supported by Grants-in-Aid for Scientific Research (C) 23592054 (to T.M.) from the Japan Society for the Promotion of Science (JSPS KAKENHI Grant Number 23592054).

Disclosures: Authors have nothing to disclose with regard to commercial support.

Received for publication Feb 13, 2013; revisions received April 20, 2013; accepted for publication May 10, 2013; available ahead of print July 15, 2013.

Address for reprints: Teruaki Mizobuchi, MD, Department of General Thoracic Surgery, Graduate School of Medicine, Chiba University, 1-8-1 Inohana, Chuo-ward, Chiba City, Chiba Prefecture, Japan 260-8670 (E-mail: tmizobuchi@faculty. chiba-u.jp).

$0022-5223 / \$ 36.00$

Copyright (c) 2013 by The American Association for Thoracic Surgery

http://dx.doi.org/10.1016/j.jtcvs.2013.05.038
}

the number of resected subsegments ${ }^{4}$ or segments ${ }^{5}$ has been shown to have excellent correlation with actual postoperative values. Because candidates for the living donor are healthy and relatively younger than lung cancer patients, we expected a better recovery of remaining lungs after the donor surgery as well as a smooth postoperative course without any severe complications. We previously reported that the postoperative pulmonary function of the donors was significantly better than the estimated values. ${ }^{6}$

The purpose of our study was to elucidate the compensatory phenomena in remnant lung after pulmonary resection. Because actual evaluation of remnant lung tissue cannot be performed, a noninvasive method is necessary for an evaluation of the quantity of lung after major pulmonary resection.

Recently, radiologic lung density has been used as a parameter of the severity of chronic obstructive disease because lung attenuation in computed tomography (CT) is predisposed to reflect the quantity of lung tissue, and actually correlates with disease severity. ${ }^{7,8}$ More recently, radiologically estimated lung weight was thought to be a significant parameter to determine the severity of acute respiratory distress syndrome, ${ }^{9}$ which is calculated by 


\section{Abbreviations and Acronyms \\ CLG = compensatory lung growth \\ COPD $=$ chronic obstructive pulmonary disease \\ $\mathrm{CT}=$ computed tomography \\ DLCO $=$ diffusing capacity for carbon monoxide \\ FEV1 = forced vital capacity \\ $\mathrm{FVC}=$ forced expiratory volume in 1 second \\ LDLLT $=$ living-donor lung transplantation}

lung volume and density. ${ }^{10}$ In this study, therefore, we also used the concept of radiologic estimation of lung weight for evaluation of the compensation.

\section{MATERIALS AND METHODS}

\section{Experimental Designs and Patients}

A consecutive series of 35 living donors underwent a right or left lower lobectomy for LDLLT in Kyoto University Hospital from 2008 to 2011. The 35 donors who met the donor selection criteria ${ }^{6}$ were examined retrospectively with regard to spirometry (forced vital capacity [FVC], forced expiratory volume in 1 second [FEV1], and diffusing capacity for carbon monoxide [DLCO]), 3-dimensional computed tomographic volumetry (mL), and mean CT numbers (Hounsfield units) before and more than 1 year after the surgery. The CT images were obtained during a single respiratory phase at the end of maximum inspiratory effort using a multidetector Aquilion 64 CT scanner (Toshiba Medical Systems, Tochigi, Japan). Whole-lung scans were performed at a peak tube voltage of $120 \mathrm{kVp}$, with variable milliamperes setting using an automatic exposure control system (standard deviation, 8.5). Contiguous, 0.5-mm-thick images, reconstructed using a standard lung reconstruction algorithm (FC 51), were used for volumetric analysis. Calibration of Hounsfield units was performed by the manufacturer's engineers. ${ }^{11}$ This retrospective study was approved by the Ethical Review Board of Chiba University (qualification no. 1362) and Kyoto University (qualification no. E1531).

\section{Radiologic Lung Evaluation}

Volume and mean Hounsfield units of the lung were obtained automatically from the AZE Work Station (AZE Ltd, Tokyo, Japan). The weight of the lung was calculated as follows: lung volume $(\mathrm{mL}) \times$ average radiologic lung density $(\mathrm{g} / \mathrm{mL})$; the average density of the lung was determined as follows: (mean CT number +1000$) / 1000$, because the estimated mean density was based on the linear relationship between Hounsfield number and actual density ${ }^{10}$ (Figure 1). The earlier-described radiologic analysis was performed on both the surgical and contralateral sides (Figure 2).

\section{Calculation of Predicted Postoperative FVC, FEV1, and DLCO}

Simplified prediction of postoperative pulmonary function based on the number of resected segments ${ }^{5}$ has been shown to have excellent correlation with the actual postoperative value. We previously proposed a method using calculated FVC by the number of segments. ${ }^{2,12}$ We applied the prediction based on the resected segments for postoperative spirometric and radiologic parameters (Figure 2). In detail, for the spirometric parameters, a prediction was made by the following equation: predicted value $=$ preoperative value $\times(19$ - number of resected segments $) / 19$. For the volumetric and radiologic lung weight analysis, a prediction for each side was made as follows: the predicted value for the right side $=$ the preoperative value of the right side $\times(10-$ number of resected segments)/10; and the predicted value for the left side $=$ the preoperative value $\times(9-$ number of resected segments $) / 9$.

\section{Statistical Analysis}

Statistical analysis was performed using the StatView (version 4.5) software package (Abacus Concepts, Berkeley, Calif). All values are expressed as means \pm standard error. The data were evaluated using the Student $t$ test between estimated postoperative values and actual postoperative values. A $P$ value less than .05 was considered statistically significant.

\section{RESULTS}

\section{Demographic Data of Living Lung Donors}

The living lung donors were $41.1 \pm 12.1$ years old and had no significant medical history or active medical history. They were nonsmokers or current smokers who were required to stop smoking at the time of their offer to donate a lung, and their smoking cessation continued after donor lobectomy. Their mean pack-year index was $2.8 \pm 7.6$. Preoperative spirometric parameters such as FVC, FEV1, and DLCO were normal (Table 1).

\section{Differences Between the Predictive and Actual \\ Postoperative FVC, FEV1, and DLCO}

Postoperative FVC, FEV1, and DLCO were significantly higher than estimated values by $17.3 \% \pm 10.2 \%$ $(P<.0001), 14.7 \% \pm 10.2 \%(P<.0001)$, and $10.9 \% \pm$ $16.2 \%(P<.002)$, respectively (Table 2$)$. Our updated data show the same trend: postoperative pulmonary function of the donors was significantly better than the estimated values reported previously. ${ }^{6}$

\section{Validation of Concept of the Radiologic Lung Weight}

Before clinical investigation, radiologic lung weight was validated in healthy volunteers. Five healthy volunteers underwent a CT scan at 3 respiratory phases, as follows: maximum inspiration, middle position, and maximum expiration, and lung volume, the estimated lung density, and radiologic lung weight at each respiratory phase was evaluated. From the phase of maximum inspiration to that of maximum expiration, lung volume was reduced whereas the estimated lung density increased. As a result, the estimated radiologic lung weight among the 3 respiratory phases was constant (data not shown). This result agreed with our hypothesis that radiologic lung weight is constant at any respiratory phase.

\section{An Example of CT Analysis Before and After a Right Lower Lobectomy}

The radiologic analysis on the surgical side was performed using the AZE Work Station, which computed that the lung volume and the mean Hounsfield units (CT numbers) were $2460 \mathrm{~mL}$ and -830 , respectively. Then the radiologic lung density and weight were calculated using the formulas as shown in Figure 1, which were $0.17 \mathrm{~g} / \mathrm{mL}$ and $418 \mathrm{~g}$, respectively (Figure 2, A). A postoperative prediction of the pulmonary function and 


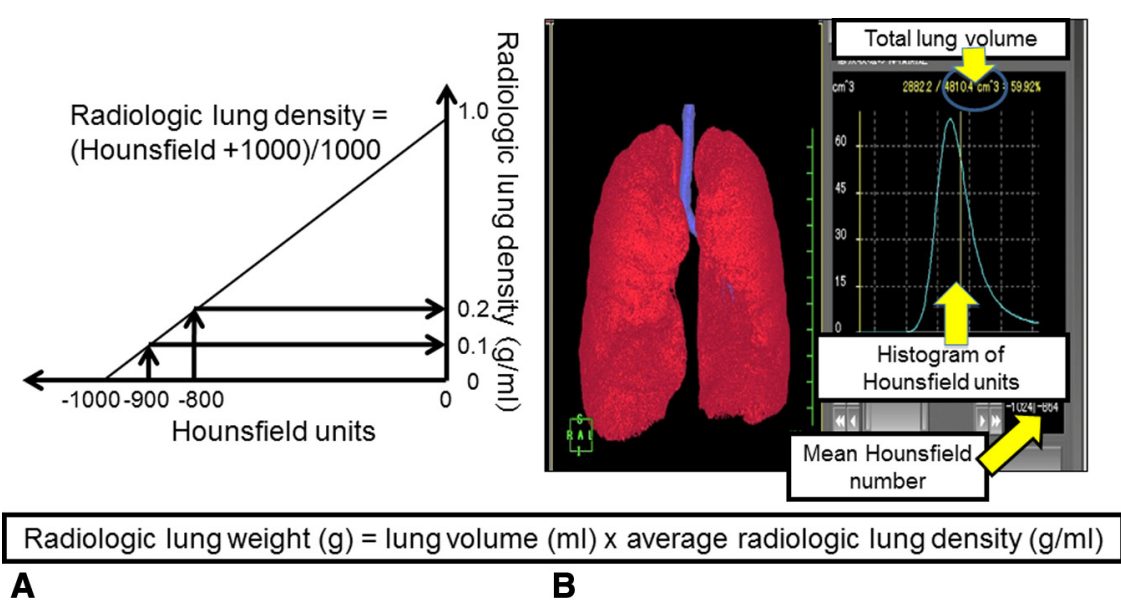

FIGURE 1. Calculation of radiologic lung density and weight. A, Radiologic lung density is based on the linear relationship between the Hounsfield number (CT number) and the actual density. B, Lung volumes $(\mathrm{mL})$ and the mean Hounsfield number of a region of interest are obtained using the computer work station.

the radiologic parameters was made based on the number of resected segments. Predicted values of the lung volume and radiologic lung weight were $1230 \mathrm{~mL}$ and $209 \mathrm{~g}$, respectively (Figure 2, B). One year after the surgery, CT volumetry showed enlargement of the remaining lungs and the volume was calculated as $1570 \mathrm{~mL}$, which was larger than the estimation by $27.6 \%$. The lung weight was calculated as $236 \mathrm{~g}$, which was heavier than the estimated value by $12.9 \%$ (Figure $2, C$ ).

\section{Postoperative Volume and Weight of the Remnant Lungs}

On the surgical side, postoperative lung volume (1890 \pm $540 \mathrm{~mL}$ ) was significantly higher than the estimated value $(1230 \pm 270 \mathrm{~mL})$ by $54.4 \% \pm 30.4 \%(P<.0001)$, and the postoperative lung weight $(270 \pm 55.2 \mathrm{~g})$ also was higher than the estimated value $(210 \pm 32.7 \mathrm{~g})$ by $28.1 \%$ $\pm 15.7 \%(P<.0001)$ (Figure 3$)$. On the contralateral side, the postoperative lung volume $(1270 \pm 290 \mathrm{~mL})$ was

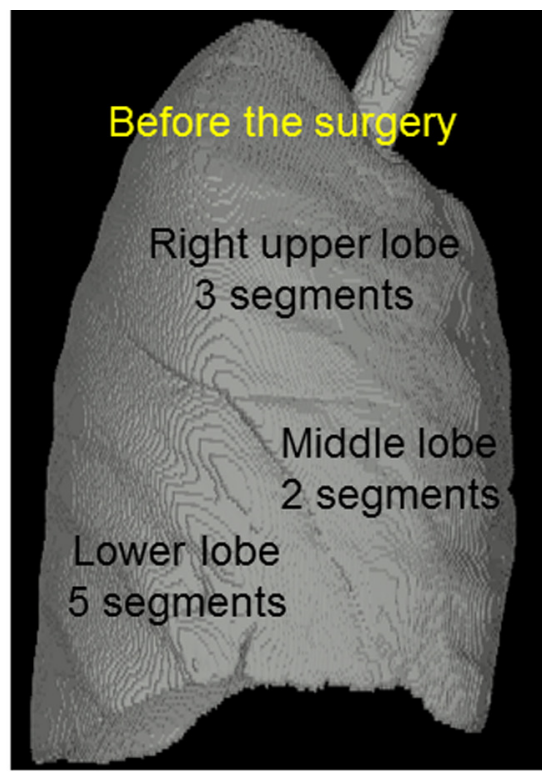

A

\section{Lung volume:}

Mean Hounsfield units:

Average radiologic lung density: $0.17 \mathrm{~g} / \mathrm{ml} \rightarrow$ Radiologic lung weight:

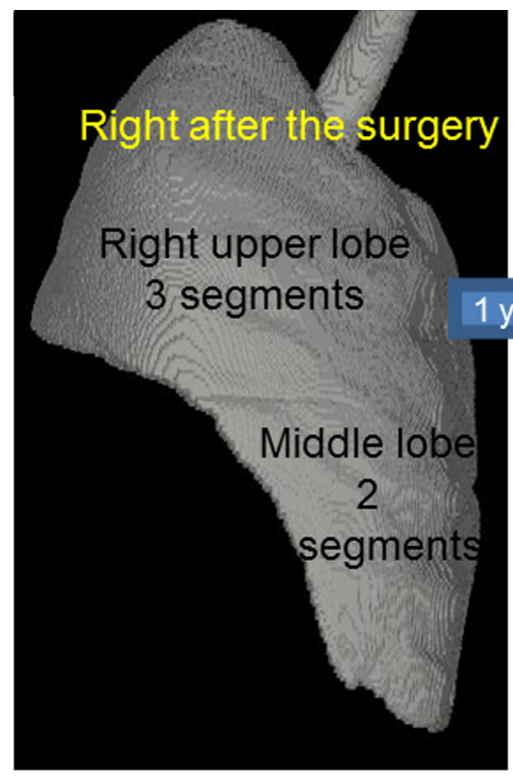

B

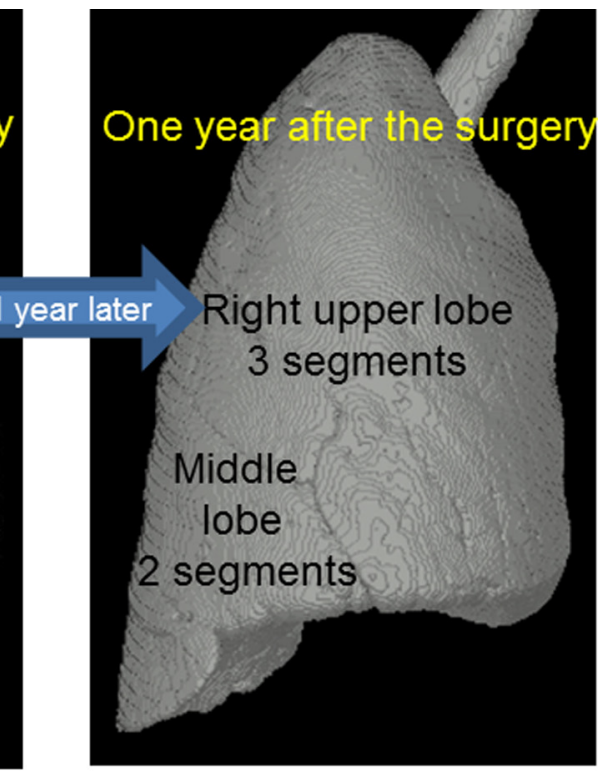

C

FIGURE 2. An example of CT analysis before and after a right lower lobectomy. The work station computes the lung volume and the mean Hounsfield number. The radiologic lung density and weight were calculated using the in the Materials and Methods section: (A) preoperative state, (B) the predicted postoperative state, and $(\mathrm{C})$ the 1-year postoperative state. 
TABLE 1. Patient characteristics

\begin{tabular}{lc}
\hline & Living lung donors \\
\hline Age (y) & $41.1 \pm 12.1$ \\
Sex (male/female) & $16 / 19$ \\
Smoking history (pack-year) & $2.8 \pm 7.6$ \\
Surgery & RLL, 19; LLL, 16 \\
Number of resected subsegments & $4.5 \pm 0.5$ \\
Spirometry (presurgery): & \\
$\quad$ FVC (L) & $3.8 \pm 0.8$ \\
FEV1 (L) & $3.1 \pm 0.6$ \\
FEV1\% (\%) & $81.7 \pm 5.7$ \\
$\quad$ DLCO (mL/min/mm Hg) & $24.5 \pm 5.9$ \\
Mean postoperative time to re-evaluation (y) & $1.0 \pm 0.03$ \\
\hline$R L L$, Right lower lobectomy; $L L L$, left lower lobectomy; $D L C O$, diffusing capacity \\
for carbon monoxide.
\end{tabular}

significantly higher than the estimated value $(960 \pm 200$ $\mathrm{mL})$ by $12.6 \% \pm 15.3 \%(P<.0001)$, but the postoperative weight $(380 \pm 540 \mathrm{~g})$ was comparable with the estimated value $(390 \pm 510 \mathrm{~g})$ by $-2.3 \% \pm 8.8 \%(P=.07)$ (Figure 4).

\section{DISCUSSION}

Accurate prediction of pulmonary reserve is indispensable for the evaluation of tolerability of patients for lung resection. Although various ways have been proposed to predict postoperative lung function, a simple calculation based on the number of resected subsegments ${ }^{4}$ or segments ${ }^{5}$ has been widely accepted because of good feasibility and precision. This study also supports this simple calculation because excellent correlations of predictions and actual postoperative values of FVC and FEV1 were shown (data not shown). However, we directed our attention to the underestimation of the prediction not only of FVC and FEV1 but also of DLCO. We reported the sequential recovery of postoperative pulmonary function at 3, 6, and 12 months after surgery; there was no significant difference between patients with right and left lobectomies at any time point. ${ }^{6}$ We selected the time point of 1 year after surgery for evaluation of compensatory phenomena because no donors reported significant pain at that time, nor were any CT findings such as pleural effusion, atelectasis, and/or other pulmonary diseases present.

In healthy individuals, routine prediction of postoperative spirometric parameters would be underestimated. The traditional prediction method, using the number of resected segments, was established by values determined in lung cancer patients, most of whom are smokers. Lower values are to be expected in patients with long smoking histories, as a result of their underlying lung disease and fewer postoperative compensatory mechanisms available. Use of these predicted values for healthy individuals therefore would be expected to lead to underestimation because healthy lungs are able to compensate properly after resection. In fact, we previously reported that the postoperative spirometric parameters and the lung volume on 3-dimensional CT tended to be higher than expected in healthy individuals. ${ }^{11}$ The observed actual values in the present study with healthy donors actually may be seen as the true reference postoperative values, and should not be interpreted as an increase from the predicted values. In the present analysis, the quantity of lung tissue, expressed as lung weight, was investigated further.

Sekine et $\mathrm{al}^{13}$ reported that the prediction of spirometric parameters after lower lobectomy tends to be overestimated in patients with chronic obstructive pulmonary disease (COPD) (actual/predicted, 1.15), but not in those without COPD (actual/predicted, 0.98). However, in the present series of living donors undergoing lower lobectomy, the spirometric parameters (FVC, FEV1, and DLCO) after surgery were all higher than predicted. This discrepancy may be owing to differences in patient age or smoking habits. The living donors in our study were approximately 20 years younger than the non-COPD patients with lung cancer in the study by Sekine et $\mathrm{al}^{13}$ (mean age, 41.1 vs $62.3 \mathrm{y}$ ), and all of our patients were non- or ex-smokers (mean pack-year index, 2.8). In contrast, $57.9 \%$ of the nonCOPD lung cancer patients in the study by Sekine et $\mathrm{al}^{13}$ were smokers. Ueda et $\mathrm{al}^{14}$ showed a smaller impact on postoperative pulmonary volume after lower lobectomy, compared with upper lobectomy, using CT-based parameters and spirometry; their finding is consistent with our hypothesis. Stronger mechanical stretch would occur after right lower lobectomy than after right upper lobectomy because a larger volume difference is created between the thoracic cavity and the remnant lung, resulting in greater compensatory lung growth. Therefore, the ability to better predict true postoperative pulmonary function is needed; the evaluation of lung weight, volume, and density will help to better refine this prediction.

It generally has been accepted that lungs cannot regenerate in mature human beings and the restored postoperative pulmonary function is attributed to a recruitment of the

TABLE 2. Differences between the predictive and actual postoperative FVC, FEV1, and DLCO values

\begin{tabular}{lcccc}
\hline & \multicolumn{1}{c}{ Predictive value } & Actual postoperative value & Differences & $\boldsymbol{P}$ value \\
\hline FVC & $2920 \pm 600 \mathrm{~mL}$ & $3450 \pm 880 \mathrm{~mL}$ & $17.3 \% \pm 10.2 \%$ & $<.0001$ \\
FEV1 & $2380 \pm 470 \mathrm{~mL}$ & $2740 \pm 610 \mathrm{~mL}$ & $14.7 \% \pm 10.2 \%$ \\
DLCO & $18.6 \pm 4.3 \mathrm{~mL} / \mathrm{min} / \mathrm{mm} \mathrm{Hg}$ & $20.4 \pm 4.9 \mathrm{~mL} / \mathrm{min} / \mathrm{mm} \mathrm{Hg}$ & $10.9 \% \pm 16.2 \%$ & $<.0001$ \\
\hline
\end{tabular}

$F V C$, Forced expiratory volume in 1 second; $F E V I$, forced vital capacity; $D L C O$, diffusing capacity for carbon monoxide. 

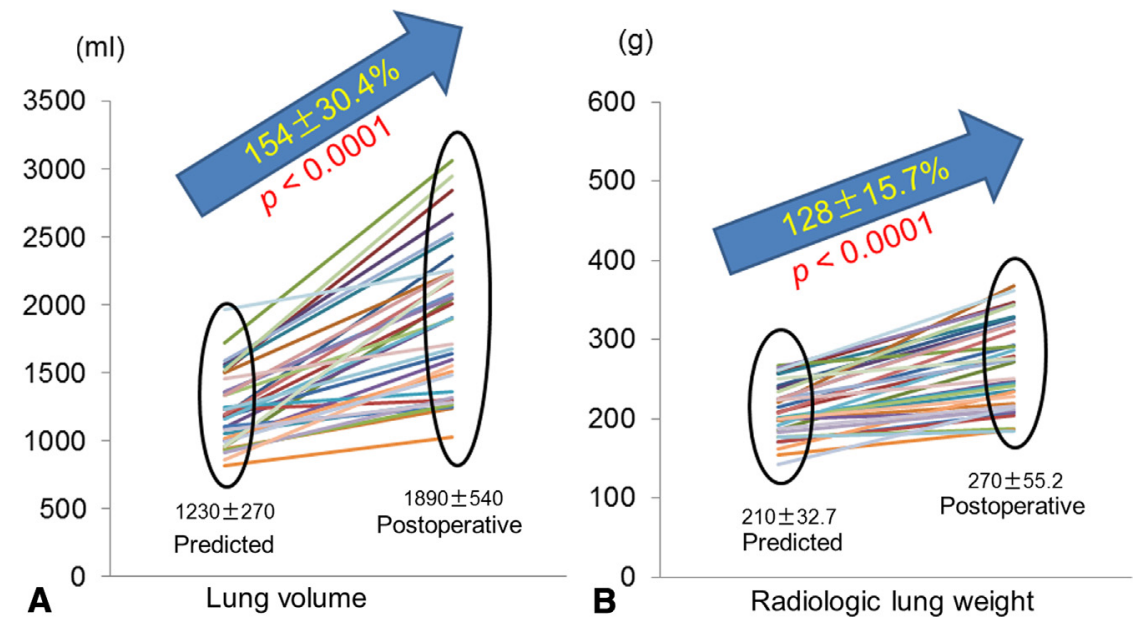

FIGURE 3. Postoperative recovery of lung volume and radiologic lung weight on the surgical side compared with the predicted values. Predicted postoperative values of the following: (A) lung volume, and (B) lung weight.

remaining lungs such as hyperinflation or augmented circulation. After a major lung resection, however, strong mechanical stretch, shear stress, and a variety of growth factors are induced in the remnant lung, and those are known to be driving forces for compensatory phenomena, and was called compensatory lung growth (CLG) in animal models. ${ }^{15-17}$ Several basic experiments clearly showed that alveolar epithelial cells and endothelial cells showed proliferative responses to artificial mechanical stretch, ${ }^{18,19}$ and the lung usually suffered from artificial mechanical stretch at the time of mechanical ventilation during surgery and in the postoperative state. After lung resection, the remnant lung hyperinflates to take up the space within the thoracic cavity. The cavity initially is suctioned by continuous negative pressure supplied by the surgical drain; the negative pressure is sustained for a long time after removal of the drainage tube, resulting in chronic mechanical stretch on the remnant lung tissue. Therefore, the clinical question was raised of whether the surplus function detected in the postoperative spirometer is attributed to so-called CLG or not. The purpose of our study was to provide radiologic evidence of CLG by means of lung volume and radiologic lung weight in human adults.

Recently, we reported a CLG model of pneumectomized rats in which the observed CLG might be attributed mainly to regeneration of supportive tissues but not alveoli, and a restoration of alveolar density is required with supplementation of the cellular source. ${ }^{16}$ If CLG is real in adult mammals, it hardly might be accompanied by regeneration of alveoli, which requires more factors than a lung resection. However, our animal experiment clarified that lung resection itself triggers dynamic modulations of numerous gene expressions, a number of which universally are related to cellular proliferation and differentiation. Even human

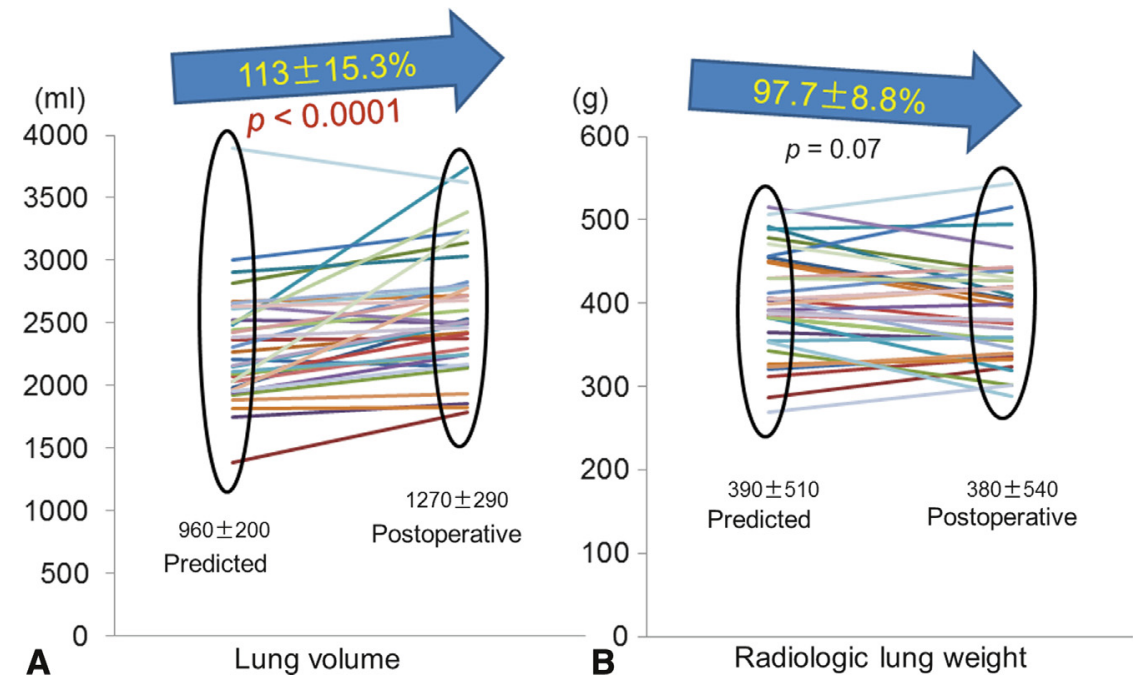

FIGURE 4. Postoperative recovery of lung volume and radiologic lung weight on the contralateral side of the surgery compared with the predicted values. Predicted postoperative values of the following: (A) lung volume, and (B) lung weight. 
adult lungs show an ability to repair themselves or regenerate in case of destruction by inflammation or primary injury; however, it is difficult to directly prove the capability of regeneration in adult human lung. Butler et $\mathrm{al}^{20}$ reported evidence of adult lung growth in human beings by serial CT and magnetic resonance imaging with the use of hyperpolarized helium-3 gas. Toyooka et $\mathrm{al}^{21}$ reported that a 10 year-old boy who underwent a lobar lung transplantation from a living adult donor showed constantly increased pulmonary function in association with his physical growth (increases in weight and height). These reports indicate that the adult human lung can grow, given the right environment. These results also prompted us to investigate the CLG phenomena in the clinical setting.

In this study, we obtained relatively uniform data from 35 adult healthy human beings who underwent a right or left lower lobectomy in the case of LDLLT. These patients were relatively younger and less exposed to smoking as compared with lung cancer patients who undergo lobectomy. The present study showed apparent differences in postoperative radiologic parameters between the surgical side and other side, and these data indicate that pulmonary resection causes significant restoration of volume and lung weight. Such changes in volume on the surgical side were explained by hyperinflation of the remnant lung to make up for the extra thoracic space. In the present data, surplus weight was recognized only on the surgical side, but not on the other side. Regarding changes in weight (or density), 2 possibilities are hypothesized; one is the association of a proliferative response of some tissues of the remnant lung, another is an increase in pulmonary circulation. The present study cannot answer this issue; however, the changes in total of the remnant lung would deserve an enlargement of the size and weight on the surgical side resulting from the compensation, which may be an inborn capability of hypertrophic phenomena of lungs.

Although the postoperative restoration of parameters such as FVC/FEV1/DLCO, lung volume, and radiologic lung weight were shown in this study, a change in oxygen uptake capability, which is an essential pulmonary function, was not examined. Nagamatsu et $\mathrm{al}^{22}$ reported the recovery of exercise capacity and pulmonary function a longtime after lobectomy for lung cancer. They periodically investigated parameters of maximum oxygen uptake as maximum exercise capacity and anaerobic threshold as moderate exercise capacity before and after pulmonary lobectomy. Interestingly, it was shown that maximum oxygen uptake and anaerobic threshold decreased just after surgery, but recovered to a preoperative level 1 year after surgery. The mechanism of the functional restoration also may be linked to the hypertrophic changes recognized in this study.

In conclusion, we evaluated radiologic parameters such as lung volume and weight and found a possible significant hypertrophic change of the ipsilateral remnant lung. This study contributes to the understanding of human lung biology, however, further studies are needed for validation that the radiologic lung weight change corresponds to the quantity of lung tissue.

\section{References}

1. Starnes VA, Barr ML, Cohen RG, Hagen JA, Wells WJ, Horn MV, et al. Livingdonor lobar lung transplantation experience: intermediate results. $J$ Thorac Cardiovasc Surg. 1996;112:1284-90.

2. Date H, Aoe M, Nagahiro I, Sano Y, Andou A, Matsubara H, et al. Living-donor lobar lung transplantation for various lung diseases. J Thorac Cardiovasc Surg. 2003;126:476-81.

3. Cohen RG, Barr ML, Schenkel FA, DeMeester TR, Wells WJ, Starnes VA. Living-related donor lobectomy for bilateral lobar transplantation in patients with cystic fibrosis. Ann Thorac Surg. 1994;57:1423-7.

4. Nakahara K, Monden Y, Ohno K, Miyoshi S, Maeda H, Kawashima Y. A method for predicting postoperative lung function and its relation to postoperative complications in patients with lung cancer. Ann Thorac Surg. 1985;39:260-5.

5. Zeiher BG, Gross TJ, Kern JA, Lanza LA, Peterson MW. Predicting postoperative pulmonary function in patients undergoing lung resection. Chest. 1995;108: 68-72.

6. Chen F, Fujinaga T, Shoji T, Sonobe M, Sato T, Sakai H, et al. Outcomes and pulmonary function in living lobar lung transplant donors. Transpl Int. 2012;25: 153-7.

7. Akira M, Toyokawa K, Inoue Y, Arai T. Quantitative CT in chronic obstructive pulmonary disease: inspiratory and expiratory assessment. AJR Am J Roentgenol. 2009; 192:267-72.

8. Yamashiro T, Matsuoka S, Bartholmai BJ, San José Estépar R, Ross JC, et al. Collapsibility of lung volume by paired inspiratory and expiratory CT scans: correlations with lung function and mean lung density. Acad Radiol. 2010;17: 489-95.

9. ARDS Definition Task Force. Acute respiratory distress syndrome: the Berlin definition. JAMA. 2012;307:2526-33

10. Gattinoni L, Caironi P, Pelosi P. What has computed tomography taught us about the acute respiratory distress syndrome? Am J Respir Crit Care Med. 2001;164: 1701-11.

11. Chen F, Kubo T, Shoji T, Fujinaga T, Bando T, Date H. Comparison of pulmonary function test and computed tomography volumetry in living lung donors. J Heart Lung Transplant. 2011;30:572-5.

12. Date H, Aoe M, Nagahiro I, Sano Y, Matsubara H, Goto K, et al. How to predict forced vital capacity after living-donor lobar-lung transplantation. J Heart Lung Transplant. 2004;23:547-51.

13. Sekine Y, Iwata T, Chiyo M, Yasufuku K, Motohashi S, Yoshida S, et al. Minimal alteration of pulmonary function after lobectomy in lung cancer patients with chronic obstructive pulmonary disease. Ann Thorac Surg. 2003;76:356-61.

14. Ueda K, Tanaka T, Hayashi M, Li TS, Kaneoka T, Tanaka N, et al. Compensation of pulmonary function after upper lobectomy versus lower lobectomy. J Thorac Cardiovasc Surg. 2011;142:762-7.

15. American Thoracic Society. Mechanisms and limits of induced postnatal lung growth. Am J Respir Crit Care Med. 2004;170:319-43.

16. Wada H, Yoshida S, Suzuki H, Sakairi Y, Mizobuchi T, Komura D, et al. Transplantation of alveolar type II cells stimulates lung regeneration during compensatory lung growth in adult rats. J Thorac Cardiovasc Surg. 2012;143:711-9.

17. Kubo H. Molecular basis of lung tissue regeneration. Gen Thorac Cardiovasc Surg. 2011;59:231-44.

18. Hegeman MA, Hennus MP, Hejinen CJ, Specht PA, Lachmann B, Jansen NJ, et al. Ventilator-induced endothelial activation and inflammation in the lung and distal organs. Crit Care. 2009;13:R182.

19. Taylor SC, Lawrence GG, Khasgiwala A, Marguiles SS. MAPk activation modulates permeability of isolated rat epithelial cell monolayers following cyclic stretch. PLoS One. 2010;5:e10385.

20. Butler JP, Loring SH, Patz S, Tsuda A, Yablonskiy DA, Mentzer SJ. Evidence for adult lung growth in humans. N Engl J Med. 2012;367:244-7.

21. Toyooka S, Sano Y, Yamane M, Oto T, Okazaki M, Kusano KF, et al. Long-term follow-up of living-donor single lobe transplantation for idiopathic pulmonary arterial hypertension in a child. J Thorac Cardiovasc Surg. 2008;135:451-2.

22. Nagamatsu Y, Maeshiro K, Kimura NY, Nishi T, Shima I, Yamana H, et al. Longterm recovery of exercise capacity and pulmonary function after lobectomy. J Thorac Cardiovasc Surg. 2007;134:1273-8. 